\author{
1) Perm State University \\ 15 Bukirev St., Perm, 614990, Russia \\ E-mail: romanphyl@gmail.com \\ ORCID: 0000-0003-4564-9973 \\ ${ }^{2)}$ Perm State University \\ 15 Bukirev St., Perm, 614990, Russia \\ E-mail: lanaschust@mail.ru \\ ORCID: 0000-0002-8318-7864
}

Received 7 July 2019; accepted 10 September2019; published 30 September 2019

\begin{abstract}
The proposed article analyzes the morphological characteristics of the vocabulary of Russian common jargon and French common argot. A comparison of two differently structured languages demonstrates the possibility of isolating instatives, words that actualize the state and are emotionally expressive. The proportionality of instatives is characterized by dualism. The common jargon/ common argo fixes a change in the literary-normative status, showing specificity at the paradigmatic and syntagmatic levels. The authors also focus on word formation issues, in which literary and non-literary tendencies are observed. In colloquial speech, word formation is characterized by originality and multidimensionality and appears as the most dynamic sphere of the language. French colloquial speech is characterized by the use of word-forming elements structurally distanced from the literary language. Russian common jargon is structurally less distanced from literary and colloquial vocabulary. The article presents the main trends in the interaction of literary and non-literary subsystems of the two languages.
\end{abstract}

Key words: Russian common jargon; French common argot; morphological analysis; colloquial speech; instative; Russian; French

How to cite: Khorosheva N.V., Shustova S.V. (2019). Morphological analysis of vocabularyof Russian common jargon and French common argot. Research Result. Theoretical and Applied Linguistics, V.5 (3), 44-59, DOI: 10.18413/2313-89122019-5-3-0-5

\section{Введение (INTRODUCTION)}

Современная научная парадигма не мыслима без широкой разработки круга вопросов, связанных с социальной природой языка. Вместе с тем изучение социальной дифференциации языка не будет адекватным и исчерпывающим без учета диалектики прерывного и непрерывного, общего и особенного, объективного и субъективного. Интерес к проблемам взаимодействия форм существования языка и образующихся вследствие этого промежу- точных языковых образований, а также детерминированности данных процессов социальной сущностью человека не является случайным.

Во-первых, это обусловлено социально-историческим и социальнокультурным контекстом современности, под воздействием которого во многих языках наблюдаются тенденции к демократизации литературной нормы. Объективно это выражается в перемещении явлений периферийных, маргинальных в направле- 
нии к центру системы, а, следовательно, в расшатывании литературной нормы, в усилении вариативности, в перераспределении функций основных форм существования языка.

Проблема подобных языковых сдвигов является и в настоящее время весьма актуальной, что находит отражение в работах, посвященных исследованию жаргона, арго, сленга (Герд 2016; Ерофеева 1991, 2018; Малинина 2015; Добриева, Измайлова 2017; Малькова 2018).

\section{Основная часть (MAIN PART)}

Цель работы - выявить и описать морфологическую специфику лексики русского общего жаргона и французского общего арго. В условиях российской социальной действительности середины 80-х 90-х гг. диффузные тенденции между литературным языком и нелитературными подсистемами приняли гипертрофированную форму. Попытка научно осмыслить резкий всплеск жаргонизации разговорной речи, наблюдавшийся в данный период, не в оценочном, но в объективноисторическом плане - является, в частности, и ответом на настоятельную потребность, диктуемую современной языковой ситуацией.

Подходы социальной диалектологии как специального направления в рамках общей социальной лингвистики, имеющего предметом устную обиходную речь во всем многообразии ее социальнобиопсихологических аспектов (Ерофеева 1991 и др. работы Пермской школы социолингвистики), целесообразно объединить со сравнительным аспектом и проанализировать предмет изучения на материале двух языков - русского и французского. Это позволяет не только глубже и шире рассмотреть вопрос о значимости выделенных промежуточных языковых образований и влиянии на них разных экстралингвистических факторов, но и определить своеобразие объектов изучения в русском и французском языках.

\section{Материал и методы исследования} (Materials and Methods)

Основной массив материала во французском языке получен путем сплошной выборки в ходе сопоставления данных словарей общего типа («Dictionnaire de langue française. Lexis» Larousse 1992, 76 тыс. единиц) и дифференциального типа (Colin, Mével, Leclère «Dictionnaire de l'argot» Larousse 1992 (DAL), 6,5 тыс. единиц). Согласно концепции исследования, изучаемый лексический пласт - французское общее арго - представлен единицами арготического происхождения, которые функционируют как просторечные или фамильярные, о чем свидетельствует соответствующая помета в словаре французского языка («рор.» или «fam.»). В ходе такой сопоставительной выборки было выявлено около 2 тыс. лексических единиц общего арго. Это, по-видимому, свидетельствует о том, что общее арго во французском языке представляет собой весьма значительный пласт стилистически сниженной лексики, входящий в систему литературного языка в составе экспрессивного просторечия.

Включение общего арго в словарь французского языка (традиционно одного из самых «нормализованных» языков в Европе), вероятно, обусловлено, с одной стороны, продолжающейся тенденцией к «расшатыванию» литературной нормы (под влиянием социальной динамики), свойственной многим современным языкам, а, с другой стороны, определенной нейтрализацией данной лексики в разговорной речи.

Иначе осуществлялся сбор материала в русском языке. Источником трудностей при сборе материала явился динамический характер самого языкового материала, который «сопротивляется» жесткой закрепленности за какой-либо сферой употребления. Очевидно, что если в 1990-е годы, когда осуществлялась фиксация данного материала, функциональная система французского языка находилась в состоянии устойчивого равновесия (а, следовательно, статус общего арго в системе форм существования 
языка достаточно стабилен), то функциональная система русского языка, напротив, характеризовалась крайней неустойчивостью, сменой ориентиров и движением от одного состояния к другому. Поэтому любые точные числа при указании на количественную представленность общего жаргона в русском языке будут иметь скорее ориентировочное, чем конечное значение.

Большая часть общего жаргона осталась «по ту сторону» литературности и, активно функционируя в разговорной речи, не вошла в систему русской литературной лексики (в качестве просторечного или разговорного стилистического средства). Исходя из этого, мы предприняли дополнительную работу с другими источниками. В итоге при отнесении слова к общему жаргону учитывалась совокупность следующих критериев: фиксирование данного слова или значения толковыми словарями русского языка (Словарь русского языка 19851988; Ожегов1953, 1972, 1984, 1989, Ожегов и Шведова 1995 и др.); не менее чем двукратное фиксирование данного слова или значения в словарях разных жаргонов и арго русского языка (Быков 1992, Елистратов 1994, Словарь молодежного жаргона 1992, Словарь тюремно-лагерноблатного ... 1992 и др.); фиксирование слова или значения картотекой живой разговорной городской речи (Пермский государ- ственный университет); признание общеязыковой употребительности данного жаргонизма в лингвистических работах; высокая частотность употребления в городской речи. В результате данной комплексной работы был составлен языковой корпус объемом 500 единиц.

Поскольку использовался метод сплошной выборки, то данное количественное расхождение в материале исследования (2000 единиц во французском языке и 500 единиц в русском языке), повидимому, обусловлено объективными причинами (лингвистического и экстралингвистического характера).

В качестве методов использовались: метод лексикографического анализа, базирующийся на изучении материала словарей; метод морфологического анализа.

Результаты исследования и их обсуждение (Results and Discussion)

При анализе морфологического состава лексики русского общего жаргона и французского общего арго становятся очевидными, с одной стороны, общие черты объектов в двух языках, обусловленные их эмоционально-экспрессивным характером, а с другой - их специфика, связанная прежде всего с особенностями структуры русского и французского языков. Последнее наблюдается, в частности, при распределении изучаемой лексики по частям.

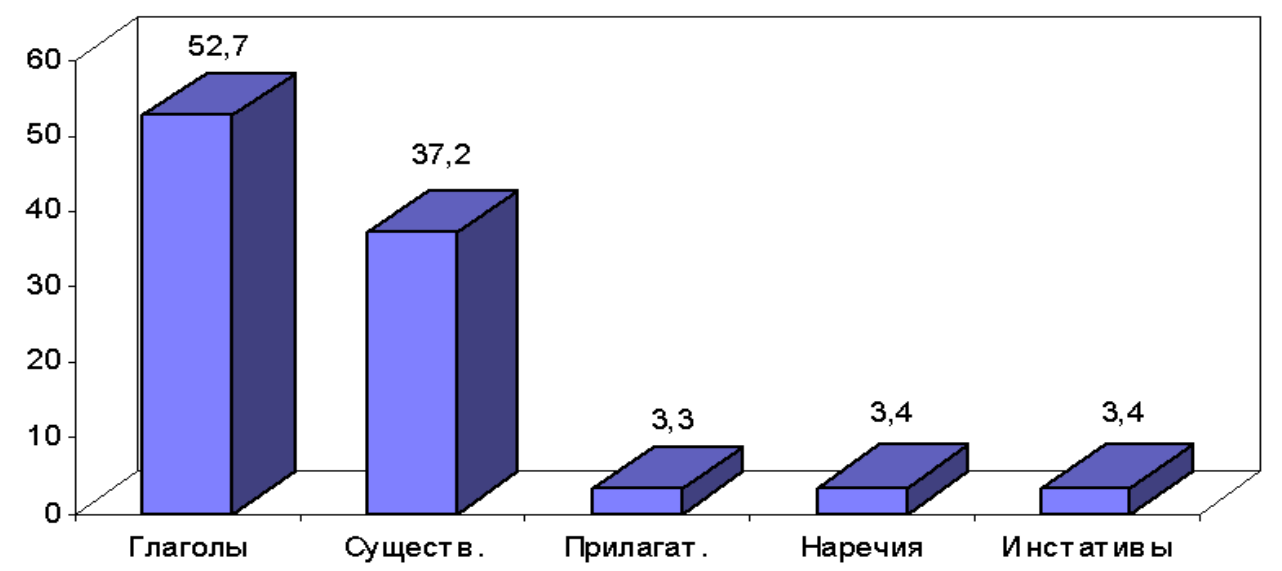

Рис. 1. Распределение лексики русского общего жаргона по частям речи (\%) Fig. 1. Distribution of vocabulary of Russian common jargon by parts of speech (\%) 
Данные показывают, что русская разговорная речь, прежде всего, активно заимствует жаргонные глаголы, которые составляют более половины исследуемой лексики общего жаргона. Это еще раз подтверждает мысль о том, что в разговорной речи наибольшей активностью и подвижностью обладают именно экспрессивные стилистически сниженные глаголы (Винокур 1968: 55). По всей видимости, эта тенденция является показателем свойственного всей системе языка роста глагольности, пропозитивности (Елистратов 1995: 160), что свидетельствует о неавтономности внелитературных подсистем от общих.

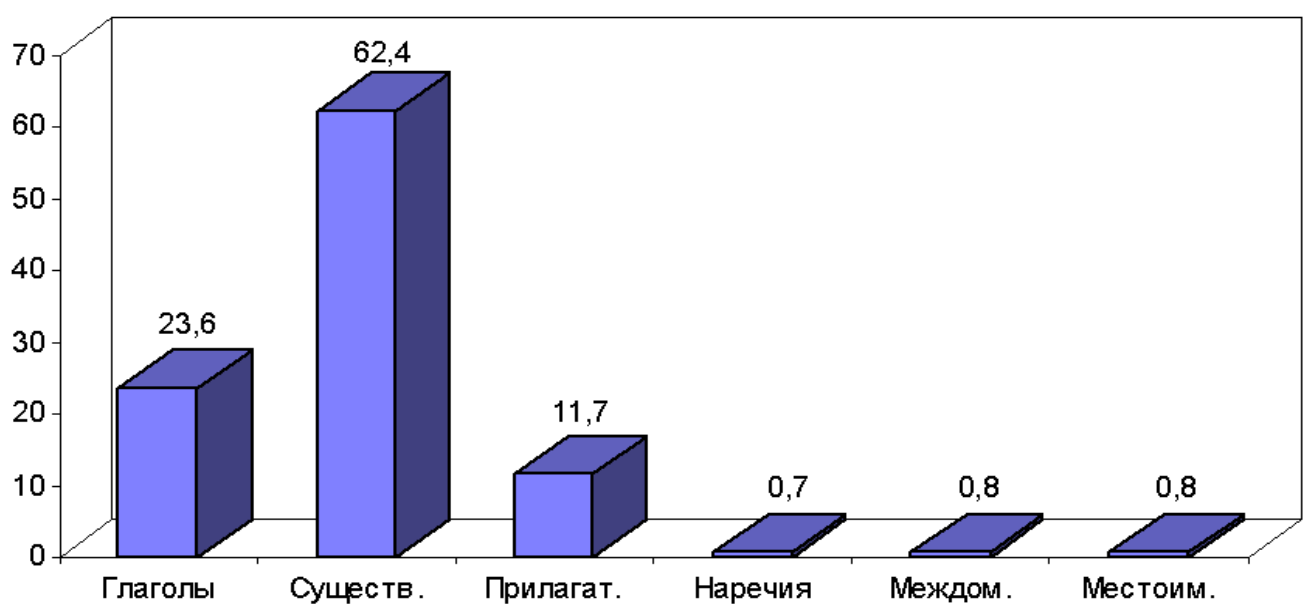

Рис. 2. Распределение лексики франиузского общего арго по частям речи (\%)

Fig. 2. The distribution of the vocabulary of the French general argo by parts of speech (\%)

Во французском общем арго большинство единиц принадлежат к именным частям речи - существительным $(62,4 \%)$ и прилагательным $(11,7 \%)$, что также отвечает основным структурным чертам французского языка.

Преобладание глаголов в русском общем жаргоне и существительных во французском общем арго есть отражение общих структурных особенностей русского и французского языков. Считая, что данные расхождения в словарном составе двух языков имеют в какой-то мере мировоззренческое основание, мы, вслед за В.Г. Гаком, не склонны видеть в этом явлении прямое свидетельство национальной ментальности и т. п. «Расхождения касаются не различий мыслительного процесса, а форм, в которые отливается мысль» (Гак 1966: 329).

Известные сложности возникли при отнесении к частям речи таких единиц русского общего жаргона, как класс, лафа, амба, кайф, облом, улет, неудобняк, отпад и т. п. В различных словарях данные слова часто фигурируют либо с комбинированной пометой («сущ. и в знач. сказ.»), либо причисляются к междометиям. По всей видимости, попытки отнести данные жаргонизмы к известным частям речи не совсем оправданы, поскольку сущность данных единиц состоит как раз в их синтаксической универсальности. Данная тенденция близка к разговорным явлениям в лексике, когда литературное слово, получая новое семантическое наполнение, становится синтаксически универсальным - см., например, разговорное «ничего» (Винокур 1968: 59). Подобные единицы целесообразнее отнести к инстативам - словам категории состояния (Тимофеев 1971: 41).

К словам-инстативам примыкает и группа предложно-падежных сочетаний: до лампочки, до фонаря, до фени, до фига, 
по фиг, не фонтан, в стельку, в дым, по кайфу, в тему, в пролете.

В целом инстативация - один из самых активных процессов в городской речи (см. Лексикографическое описание... 1994: 23), который находит свое выражение и в общем жаргоне.

Специфической особенностью французского общего арго является наличие арготических синонимов личных местоимений: 1 лицо ед. ч. - mézigue, ma pomme, ma poire, ma cerise, mon bibi, ma figure, ma fiole, ma gueule; 2 лицо ед.ч. - tézigue, ta pomme, ta poire, ta figure, ta frime. Характерно, что в общее арго проникают только местоимения 1-го и 2-го лица единственного числа. Таким образом, местоименная парадигма, будучи неполной даже в арго (Calvet, 1993: 191-192), еще более редуцируется в городской разговорной речи.

Хотя «частеречная принадлежность слова, как и отдельные грамматические категории, неотделима от лексических, морфонологических признаков» (Ковалева, Кабулова, 1995), род, переходность / непереходность, вид, возвратность могут быть объектами своеобразной игровой «аберрации». Языковую систему эти тенденции не затрагивают, но делают грамматические категории дополнительным источником экспрессии. Особенно это характерно для арго деклассированных и является, по всей видимости, тенденцией, общей для социальных диалектов разных языков (Ковалева, Кабулова, 1995; Calvet, 1993: 189-197; Verdelhan-Bourgade 1991). В самой системе языка, таким образом, содержатся потенциальные средства для создания экспрессии.

Иерархические отношения между родами имеют, как известно, объективную экзистенциальную основу. Как писал А.А. Потебня, «грамматический род принадлежит к числу общих человекообразных понятий (антропоморфических категорий), служащих для расчленения, приведения в порядок и усвоения всего содержания мысли", и “представить себе такое создание мысли иным, чем созданием "по образу и подобию своему", чем внесением в познаваемое свойств познающего, мы не в силах» (Потебня, 1968: 46).

Категория рода в арго деклассированных с необходимостью отражает презрение к женскому началу - одну из составляющих своеобразного мировоззрения арготирующих. С другой стороны, для арго характерна относительная свобода варьирования родовой принадлежности, «размытость» категории рода вообще.

В арго деклассированных, где «нет тирании правил» (Вандриес, 1937: 235), тенденция к родовым преобразованиям лексики гипертрофируется. В общем жаргоне/общем арго данная тенденция в известной мере нивелируется, поскольку общим речевым узусом не принимается избыточность и дублетность арготической лексики. Однако некоторые черты данного явления наблюдаются и в лексике общего жаргона/общего арго.

В русском общем жаргоне присутствуют существительные общего рода с яркой экспрессивной окраской: доходяга, деляга, мазила, барыга, стиляга, ханыга, шестерка и т. п. Еще более экспрессивны единицы среднего рода, которые даже имеют специфическую ритмическую организацию при сгущении негативной оценки: фуфло «грубая подделка, обман», хамло «хам».

«Снижение» часто сопровождается сменой родовой принадлежности слова путем переноса значения или суффиксации: тачка «легковой автомобиль, такси», заначка «тайник», толкучка «вещевой рынок», бандура «громоздкий предмет» и т. п.

Для французского общего арго использование экспрессивного потенциала родовой принадлежности слова более характерно, чем для русского общего жаргона. Это проявляется в целом ряде инвективных номинаций женского рода, которые обозначают лицо мужского рода: huître, andouille, demi-portion, ordure, tache, tasse, lavette и т. п. Многие арготизмы имеют 
«размытую» принадлежность к роду и фиксируются словарями с пометой «n.m. et f.» («муж. и жен. род»): avaloir (avaloire), chahut, dondon, emmerde и др. Ясно, что эта тенденция близка к просторечной семантически не нагруженной дублетности.

Общий жаргон / общее арго имеют специфику как на парадигматическом, так и на синтагматическом уровнях. Так, в лексике изучаемых промежуточных подсистем двух языков наблюдаются случаи «аберрации» категории переходности/непереходности глагола. Изменения в управлении глагола сопровождают, как правило, изменение в значении слова, остраняют его, делают экспрессивным.

Например, глаголы, являющиеся в литературном языке переходными, в жаргоне и арго, а затем в общем жаргоне, становятся непереходными: сечь «понимать, разуметь», валить «употребляется как побуждение к действию», волочь «понимать, разбираться», клепать «доносить на когол.», вкальвать «работать с большим напряжением и много», мазать «делать промахи» и т. п. Нередко при этом изменяется и литературно-нормативное образование видовых глагольных форм: косить закосить, стучать - настучать, буреть забуреть, кроить - закроить.

Используется в русском общем жаргоне и системный потенциал категории возвратности/невозвратности: кантоваться «отдыхать, бездельничать; находиться гдел.», купиться «соблазниться чем.-Л., легко поверить во что-л. и обмануться», махаться «меняться, обмениваться; драться».

Во французском общем арго также наблюдаются случаи системных сдвигов в управлении глаголов: charrier «exagérer», fouetter «puer; avoir peur», gazer "aller à toute vitesse», gratter «travailler», crever «mourir». Ряд глаголов функционируют в общем арго и как переходные, и как непереходные: bigler «jeter sur une personne ou une chose un regard d'envie; y faire attention», cuver «laisser se dissiper l'ivresse par le sommeil ou le repos; se calmer, s'apaiser», dessoûler «faire cesser son ivresse», draguer «chercher à aborder, à racoler qqn pour quelque aventure» и др. Некоторые глаголы в арго становятся возвратными: se ramasser «tomber; échouer», se bourrer «se soûler», se mouiller «se compromettre».

Однако как в русском общем жаргоне, так и во французском общем арго тенденции к «аберрации» данных грамматических категорий не являются доминирующими. Многое остается за рамками общеупотребительной разговорной лексики, не принимается городским узусом как резко противоречащее литературной языковой системе (см. использование в русских уголовных арго суффикса -ану- для видообразования без значения однократности) либо как несвободное от ярко выраженной социальной маркированности (см. глаголы craindre, assurer, употребительные в argot des jeunes как непереходные).

Наибольший интерес в исследовании структурных особенностей лексики русского общего жаргона и французского общего арго представляет словообразование - область, в которой активно участвуют как литературные, так и нелитературные тенденции.

Проблеме словообразования уделяли внимание практически все исследоватеи н,ева 1991: 55; Грачев 1995: 10-11; Елистратов, 1995: 161-175; Зайковская, Федяев, 1996; François, 1973, 1992; VendelhanBourgade, 1991; Calvet, 1994 и др.). Ученые, как правило, подчеркивают, что в целом особенности жаргонного/арготического словообразования не дают оснований считать лексику данных социальных диалектов явлением особого ряда, изолированным от общеязыковых тенденций и закономерностей.

Известно, что своеобразие разговорного словообразования заключается не в наличии особых функций, а в том, что «они обнаруживают в разговорной речи большую активность, т. е. словообразование в разговорной речи действует как 
более динамическая сфера языка» (Земская и др., 1981: 189).

Так, при образовании от литературных и нелитературных основ наиболее продуктивны те же аффиксы (преимущественно суффиксы), которые используются в общем языке. Рассмотрим особенности аффиксального словообразования в изучаемых нами объектах двух языков.

Среди структурно отмеченных единиц русского общего жаргона преобладают слова, образованные при помощи суффиксов, употребительных в разговорной речи (Земская, 1979: 112-130). Многие из них традиционно продуктивны в жаргонах и арго. Приведем список посткорневых формант лексики русского общего жаргона: - ага/яга: стиляга, общага, доходяга, деляга; - ак/як: видак, дубак, неудобняк; - ан: друган, братан, дистрофан; - яр(а): котяра; - (а)рь: кепарь; - ач: строгач, фирмач; - ай: раздолбай; - аж: подхалимаж; - (аль)ник: матюгальник, стольник; - ик: видик, шизик, гомик; - истик(а): ерундистика; - изм: вонизм, пофигизм; -ист: пофигист; к(а):заморочка, заначка, шестерка, разбор$к а$; - еж: балдеж, выпендреж; -(ов)к(а): бестолковка, тошниловка, ментовка. соображаловка (суффиксальная универбизация); - он: выпивон, закидон, закусон, музон; - ок: качок, комок, толчок, воронок; -ня: фигня; -(уш)ник/(юш)ник: видюшник; - ух(а): бормотуха, спещуха; - ун: несун.

По всей видимости, в жаргонах и арго может использоваться потенциально любая литературная словообразовательная модель (ср. Виноградова 1984: 181-182).

Характерно, что в русском общем жаргоне и французском общем арго наблюдается общая тенденция - травестирование стилистического наполнения модели. Например, обыгрывается, снижается идея «научности», «серьезности», содержащаяся в ряде книжнолитературных суффиксов: вонизм, пофигизм, иизоид, пофигист, болтология, алканавт, ерундистика; je-m'en-foutisme, je-m'en-foutiste, baisodrome, pifomètre (au pifomètre) и т. п. Смеховому снижению подвергаются во французском общем арго слова классической латыни: pedibus, illico и др.

Нередко в жаргонном/арготическом словообразовании используются макаронические приемы: подхалимаж, оживляж и т. п. Здесь смеховому снижению подвергается форманта с собирательным значением, заимствованная из французского языка в составе книжно-литературных слов, терминов (монтаж, литраж, метраж и т. п.). Такие морфологические изменения семантически не нагружены: не внося ничего в денотативное значение, «экзотические» форманты служат исключительно целям псевдоэстетизации, смехового снижения.

Среди единиц общего жаргона, образованных морфологическим способом, встречаются слова с другими «экзотическими» формантами, пришедшими из преступного арго: корефан, картофан; тройбан «тройка (оценка)», кусман «кусок». Однако такие примеры редки, поскольку чуждость, «экзотичность» суффикса препятствуют массовому распространению такой словообразовательной модели в разговорной речи.

Так как изучаемое языковое образование имеет недискретный характер, привести конечное число суффиксальных моделей, присущих русскому общему жаргону, не представляется возможным. Однако можно предположить, что, чем ближе единица своей внешней формой к литературно-разговорному экспрессивному словообразованию, тем больше у нее шансов пополнить синонимические парадигмы общего языка, войти в общеразговорный узус.

Среди префиксов в лексике общего жаргона наиболее часто встречаются следующие: бес-: беспредел, бестолковка; вы-: выбить, вылдать, вырубиться; за-: забуриться, забалдеть, завалить, завыпендриваться, завянуть, загнать, загнуть, загреметь, задолбать, задубеть, закадрить, закачаться, заложить, заколебать; о-: 
офонареть, оборзеть и т. д.; об-: обломать; от-: отмазаться, отключить, отпад, отрубиться; под-: подгрести, поднадоесть, подзаловить; при-: прикальвваться, притаранить, пришпандорить; про-: пролететь, просечь; с-: свалить, сдать, сдуть, скатать, слинять, скорешиться; у-: улет, усечь.

Префиксация наиболее характерна для системы внутриглагольного словопроизводства, и, как видим, в целом не является специфическим для изучаемой лексики явлением. Однако можно усмотреть определенные черты гипераффиксации в словах поднадоесть, подзалететь, подзаловить и т. п. в значении «надоесть», «залететь», «заловить». Такие семантически «пустые» морфемы выполняют в арго деклассированных функцию социального маркера, а в общем жаргоне - экспрессивную функцию.

Интерес представляет бессуффиксальный способ создания существительных путем отсечения инфинитивных суффиксов (нулевой суффиксации): вcnblx $<$ вспьхивать, ор < орать, промельк < промелькнуть, либо от прилагательных: наив < наивный, интим < интимнылй, примитив < примитивнылй и т. п. Особенно продуктивен этот способ словообразования в некодифицированной лексике.

В русском общем жаргоне примерами такого рода являются неформал < неформальный, отпад < отпасть, серьез < серьезный, беспредел < беспредельный, напряг $<$ напрягать, втыл < втыкать, облом < обломить, пролет < пролететь, улет < улететь (как правило, все они одно-, двухсложные).

Нулевая суффиксация выступает, таким образом, проявлением одной из актуальных тенденций в русской словообразовательной системе и привносит вместе с характерной ритмической формой яркую экспрессивную окраску.

Важной особенностью общего жаргона является то, что в его составе нет единиц, имеющих характерную для жар- гонов и арго структурную отмеченность лексем, образованных путем фонетической мимикрии и искажения звуковой формы литературных слов; усечения, сокращения, каламбурных контаминаций и других «гипервыразительных» лексем.

Исключение составляют широко употребительные бомж и зек, имеющие в своих основах аббревиатуры («без определенного места жительства» и «заключенный - з/к - зэка») (см. Хан-Пира, 1994).

В целом наблюдения показывают, что структурные особенности русского общего жаргона не противоречат основным тенденциям разговорного и экспрессивного словообразования. «Экзотические» явления в структуре изучаемой лексики малочисленны. Со структурной точки зрения проникновение лексем в общий жаргон тем вероятнее, чем меньше противоречит форма слова сложившимся общеязыковым традициям. Поэтому на периферии этого промежуточного языкового образования находятся единицы с окказиональной или «экзотической» структурной отмеченностью.

По количеству и разнообразию суффиксов, с помощью которых образованы многие структурно отмеченные единицы французского общего арго, последние в значительной степени превосходят изучаемую лексику в русском языке.

Для общего арго также в полной мере характерно использование как нейтральнолитературных, так и экспрессивноразговорных суффиксов: -eur: bêcheur, bosseur, chineur, cravateur, emmerdeur, enculeur, frimeur, baiseur, bonneteur, charrieur, chourineur, dragueur, flambeur, glandeur, licheur, peloteur, picoleur; -ard: bouffarde, cambrousard, chiard, cocard, connard, cossard, costard, crevard, flambard, flicard, cornard, guignard, jobard, nullard, nuitard, partousard; -(t)on: biffeton, dricheton, capiston, couillon, cureton, foiron, griveton, mecton, merdaillon, litron, paveton; -age: chinage, déconnage, enculage, mégotage, magouillage; -erie: chierrie, connerie, couillonnerie, dé- 
gueulasserie; -aille: boustifaille, duraille, flicaille, merdaillon, poiscaille; -asse: bidasse, birbasse, chiasse, connasse, dégueulasse, godasse, grognasse, pétasse, poufiasse, putasse; -asson: canasson; -ette: clopinette, comprenette, lavette, nénette, liquette, gigolette, margoulette, pépette, piquette, pompette; -ier: pucier, fumier, putassier; -oir/oire: dégueulatoire, foutoir, pétoir; -ade: engueulade, foirade; -ance: bectance, croustance, cuistance, gourance, jactance, boulance; isme: je-m'en-foutisme; -able: baisable; -ot: cuistot, flingot, fricot, loupiote, mendigot, péquenot, perlot, poivrot; -in: biffin, catin, chopin, frangin, popotin, purotin; -al: foutral; -ique: bordélique, merdique; -iller: bousiller; -otte: chiotte; -otter: boulotter; -aise: fichaise, foutaise; -iquet: foutriquet.

То, что качественно отличает структурные характеристики французского общего арго от русского общего жаргона, это наличие специфических арготических суффиксов: -осhe: bidoche, chinoche, valoche, patoche, pétoche; -uche: paluche; -aga: pastaga; -ouse/ouze: partouze; -o: chéro, clodo, dingo, franco, gigolo; -ouille: merdouille, bistrouille, carambouille, papouille, pedzouille; -iche: angliche, bonniche, catiche, cibiche, fortiche, а также менее peгулярных, «фантазийных» суффиксов (suffixes fantaisistes): -ar: polar; -broc: pébroc; pin: auverpin; -ax: furax; -zar: falzar; -piner: jaspiner; -toc: chinetoc, mastoc; -zingue: brindezingue; -os: débilos.

Специфику данных суффиксов составляет не столько их арготическое происхождение, сколько то, что они семантически «пусты». Не имея никакой семантической или грамматической нагрузки, данные суффиксы лишь остраняют внешний облик слова, вносят элемент языковой игры.

Аналогичные примеры встретились нам и в русском общем жаргоне (см. кусман, тройбан и т. п.). Однако, если в русском материале такие случаи единичны, то во французском общем арго мы наблюдаем более четко выраженную тенденцию. Таким образом, для французского общего арго, a, следовательно, для французской разговорной речи более характерно употребление структурно дистанцированных от литературного языка словообразовательных элементов. Включение таких единиц в словарь «Dictionnaire de langue française. Lexis» свидетельствует об их узуализации в современной французской речи и о известной «нормализации» в речевом обиходе. Ложный характер суффиксации определенной части структурно отмеченных единиц общего арго позволяет судить о их рекреативном потенциале, заложенном в необычной, экспрессивной форме.

Еще более «экзотическим» для литературного языка является прием сокрытия формы слова с помощью так называемого арготического кода. Суть этого способа словообразования состоит в трансформации внешней формы слова по известному ключу - путем перестановки слогов (verlan) или более сложных модификаций (введения дополнительных слогов и (largonji, javanais).

В общем арго присутствуют единицы, имеющие источником verlan (оборотное арго): arsouille < souillard «voyou et débauché», beur < arabe «jeune d'origine maghrébine né en France de parents immigrés»; largonji: loufoque < louf < fou; lope $<$ lopaille $<$ copaille < copain «homme lâche, capable de dénoncer ses amis» и т. п. Остранение единиц такого рода имеет крайнюю форму, поскольку используется искусственная модель. Однако затем, как правило, мотивированность таких слов, особенно слов, образованных путем сложных морфофонематических модификаций, отчасти стирается.

Распространившаяся в 80-90-е гг. употребительность verlan во многих французских арго, прежде всего в так называемых «модных» арго (parlers branchés), способствует узуализации отдельных единиц, образованных с помощью данного кода. Этому во многом способствуют средства массовой информации (пресса, телевиде- 
ние, независимые радиостанции), творчество популярных певцов (Рено Сешан и др.), кинематограф и т. д. Однако вхождение в общее арго, а тем самым приближение к норме, наблюдается преимущественно в тех случаях, когда единица заполняет номинационную лакуну.

Традиционной для французской разговорной речи является тенденция к усечению формы слова. В общем арго встречается апокопа: anar, aristo, aprème, bénef, bide, blase, blair, bouille, bourre, came, châsse, colon, cosse, der, flingue, fric, frigo, from, frusques, hash, jar, mac, marle, occase, pédé, perm, perpète, pro, porno и др. и афереза: cipal, gnon, gnard, bicot, bougnat. Часто усечение сопровождается суффиксацией (-o): apéro, convalo, prolo, proprio, réglo, prompto.

Близким к данной форме словообразования является образование от глаголов существительных с нулевым суффиксом. Регрессивная деривация дала некогда многочисленные образования в литературном языке (cri, appel, marche, gêne и т. п.), после чего сфера ее активности сузилась до просторечно-арготической коммуникации. Примеры из общего арго: bouffe < bouffer, briffe < briffer, cambriole < cambrioler, cavale $<$ cavaler, cogne < cogner, culotte < culotter, débine $<$ débiner, fourgue $<$ fourguer, gambille $<$ gambiller, guinche < guincher, défonce < défoncer, margoulin < margouliner, passe < passer, pisse < pisser, plombe < plomber, poisse < poisser и т. п. Краткость формы является источником экспрессии прежде всего за счет своей «разговорности».

В целом, однако, во французском общем арго преобладает отыменное словообразование, поскольку такова структурная тенденция, свойственная всему французскому языку (Гак 1966, : 47). Примеры из общего арго: biberonner < biberon, alpaguer < alpague, banquer < banque, becter < bec, bidonner < bidon, $($ se) biler < bile, bigophoner < bigophone, (se) biturer < biture, blairer < blair, bordéliser < bordel, butter < butte, cafter < cafard, canuler $<$ canule, caner $<$ cane, canarder
$<$ canard, castagner < castagne, chiader < chiade, chiper $<$ chipe, coffrer $<$ coffre, couillonner $<$ couillon, courser < course, cramponner < crampon, fricoter < fricot, frusquer < frusques, glavioter < glaviot, jobarder < jobard, lourder < lourde, marner < marne, pageoter < pageot, partouser < partouse, pétarder < pétard и т. п.

В русском языке, напротив, как известно, преобладает отглагольное словообразование, подтверждение чему находится и в общем жаргоне: балдеж < балдеть, вы пендреж < выпендриваться, выпивон < выпивать, закусь< закусывать, заморочка < заморочить, заначка < заначивать, качок < качаться, мазила < мазать, навар < наварить, облом < обломиться, отпад < отпасть, прикол < прикалываться, пролет < пролететь, разборка < разбирать(ся), толчок < толкаться, пусовка < тусоваться и т. п. В данном случае лексика изучаемых промежуточных языковых подсистем не отличается от любых других лексических подсистем.

Чрезвычайно характерное для французского словообразования явление конверсии находит свое выражение и в изучаемой нами лексике (во французской терминологии - dérivation impropre - несобственная деривация).

Поскольку практически всякое имя прилагательное во французском языке может быть субстантивировано, в общем арго группа существительных, образованных путем субстантивации прилагательных, а также причастий, представлена весьма широко: bouseux «paysan», carrée «chambre», belle «évasion», blanche «eau-de-vie», affreux «individu antipathique», dur «homme sans scrupule, prêt à la bagarre», jaune «briseur de grève, ouvrier qui travaille alors que les autres sont en grève», juteux «adjudant», joyeux «surnom donné naguère aux soldats des bataillons d'infanterie légère d'Afrique», affranchi «libéré de tout préjugé, de tout scrupule de conscience», fauché "se dit d'une personne qui n'a pas d'argent», frit «se dit de qqn qui est dans une situation dangereuse, qui est perdu», gonflé «qui est plein de courage, d'ardeur ou d'imprudence» и др. 
Зачастую, в силу функциональной близости, прилагательное (причастие) и производное существительное фигурируют в словарях как одна единица с пометой «adj. et n.» («прил. и сущ.»): branché, balèze, collabo, combinard, dégonflé, démerdant, dingue, dragueur, enfoiré, fada, faisandé, feignant, fêlé, flagada, foireux, fortiche, frimeur, fumiste, gaga, girond, gobeur, guignard, jobard, juif, loufoque, merdeux, bêcheur, bigleux, boche, bosseur, camé, cinglé, cossard, costaud, crevé и т. п. (около $10 \%$ от всех существительных и прилагательных).

Нередки также случаи адъективации существительных: bœuf «considérable», champion «excellent», cloche «stupide», malabar "grand, fort», marron «se dit de qqn qui exerce une profession irrégulièrement», beauf «qui témoigne l'état d'esprit de Français moyen, aux idées étroites, bornées», crack «fort, difficile», lèche-bottes «se dit d'une personne s'abaissant à des flatteries serviles», nickel «d'une propreté impeccable», nature «franc», coton «difficile», marteau «un peu fou» и т. п.; адъективации причастий Participe Présent и Participe Passé: balancé «bien fait, avec qch de fort, de solide, d'harmonieux», beurré «ivre», croulant «se dit d'une personne épuisée par son grand âge», ficelé «habillé», barbant «ennuyeux», crevant «très drôle», fumant «extraordinaire, sensationnel», givré «fou», gondolant «très drôle», enfariné «qui est dans une situation fâcheuse», gratiné «se dit de ce qui sort d'ordinaire, en bien ou en mal», lessivé «qui a perdu toute force physique ou morale», verni «qui a de la chance» и т. п. По нашим наблюдениям, при переходе в категорию прилагательных у причастий, как правило, развивается переносное значение, и они приобретают абстрактный характер.

Из других случаев конверсии в лексике французского общего арго отметим переход прилагательных в наречия: class «assez», marre «assez»; интеръективацию существительных и прилагательных: bernique, ras-le-bol, galère, chouette, barca и др.
Наиболее продуктивны префиксы а(abouler, amocher), dé- (débecter, décarrer, déconner, décramponner, dégobiller, dégrouiller, dégueuler, démerder, dépatouiller, dépuceler), en/em- (enculer, emmouscailler, engueuler), re-.

Среди других структурных особенностей изучаемой лексики французского языка отметим словосложение (avale-toutcru, baise-en-ville, bigophone, baisodrome, jean-foutre, lèche-bottes, peigne-cul, poussecailloux, pète-sec, casse-pattes, casse-pipe, casse-gueule, casse-poitrine), редупликацию (bobonne, être boulot boulot, coco, cracra, gaga, gogo. loulou, béni-oui-oui, blabla, bouiboui, flaflas, pépée, pépère, bibi, mémé, pépé, popote).

Шире, чем в русском общем жаргоне, представлено словотворчество, игра со словом. Это выразительные, а порой и остроумные, случаи контаминации (bancroche < bancal + crochu, carapater $($ se $)<$ se carrer + patte, cloporte < clore + porte, foultitude $<$ foule + multitude), фонетической мимикрии, когда обыгрывается фонетическая форма слова (marie-jeanne < marijuana, pingouins < pinceaux («pieds»), être de la pédale < pédéraste, contredanse < contravention.

Широко представлены в общем арго единицы, образованные с помощью различных системных и несистемных фонетических процессов: attiger < aquiger «exagérer», clampin < clopin «individu quelconque, plutôt lent et paresseux», entraver < enterver «comprendre», feignant $<$ feinéant «paresseux», frangin $<$ frère, licher $<$ lécher «boire», magner (se) < manier «se hâter», planquer < planter «cacher», lamper < laper «vider (un verre)» и т. п. Это свидетельствует о функциональной слитости французского арго с просторечием, с одной стороны, и о известной толерантности литературного языка к экспрессивным единицам такого рода - с другой.

Среди других способов пополнения словарного состава арго, а, следовательно, и источников общего арго отмечается ономатопея (baffe, babines, bouffer, boum, briffer, 
couic, craquer, dinguer, faf, fric-frac, kiki, bafrer, dondon, prouf и т. п.), лексикализация имен собственных (bénard, bigophone, bitos, catin, eustache, malabar, alphonse, giton, pépin, pipelet и др.).

\section{Заключение (CONCLUSIONS)}

В целом можно сделать заключение, что для существования общего жаргона в русском языке и общего арго во французском языке существуют объективные лингвистические предпосылки. Нельзя не согласиться с Л.Н.Скворцовым в том, что «жаргон (...) эволюционирует к сленгу, естественно усваивается им и находит встречные движения, укладываясь, таким образом, в рамки нормальных процессов обычной живой (...) речи» (Скворцов 1980: 182).

Если ввести операциональное понятие структурной дистанции (Барнет, 1988: 190), то при установлении дифференциального признака «наличие/отсутствие несистемных морфологических элементов» выявляется расхождение в изучаемых объектах двух языков. Русский общий жаргон структурно менее дистанцирован от литературно-разговорной лексики, чем французское общее арго от соответствующей подсистемы в этом языке. Дифференциальный признак при этом имеет градуальный характер (по степени выраженности). Во французском языке активнее используется экспрессивный потенциал «экзотических» для литературного языка средств (арготических словообразовательных элементов, арготического кода), а также просторечных по природе процессов (фонологические трансформации, различного рода искажения). «Открыто» общее арго и для словотворчества, словесной игры.

Таким образом, сопоставительный анализ морфологических характеристик русского общего жаргона и французского общего арго позволяет выявить основные тенденции взаимодействия литературных и нелитературных подсистем двух языков.

\section{Список литературы}

Барнет В. Дифференциация национального языка и социальная коммуникация // Новое в зарубежной лингвистике: Теория литературного языка в работах ученых ЧССР. М.: Прогресс, 1988. Вып. ХХ. С. 188-198.

Береговская Э. М. Социальные диалекты и язык современной французской прозы. Смоленск: Смоленский педагогический институт, 1975. $120 \mathrm{c}$.

Вандриес Ж. Язык: Лингвистическое введение в историю. М.: Государственное социально-экономическое издательство, 1937. $410 \mathrm{c}$.

Виноградова В.Н.Стилистический аспект русского словообразования. М.: Наука, 1984. $183 \mathrm{c}$.

Винокур Т. Г. Стилистическое развитие современной русской разговорной речи // Развитие функциональных стилей современного русского языка. Ред. Д. Н. Шмелев. М.: Наука, 1968. $232 \mathrm{c}$.

Гак В. Г. Беседы о французском слове (Из сравнительной лексикологии русского и французского языков). М.: Международные отношения, 1966. $351 \mathrm{c}$.

Герд А. С. Жаргон и социальная группа // Вопросы психолингвистики. 2016. № 28. C. $106-111$.

Грачев М. А. Происхождение и функционирование русского арго: Автореф. дис. ... докт. филол. наук. Санкт-Петербург, 1995. 48 с.

Добриева 3. И., Измайлова М. М. Жаргон в речи современной молодежи //Linguauniversum. 2017. № 4. C. 33-35.

Елистратов В.С. Арго и культура. М.: МГУ, 1995. $231 \mathrm{c.}$

Ерофеева Т. И. Опыт исследования речи горожан. Свердловск: Уральский университет, $1991.135 \mathrm{c}$.

Ерофеева Т. И. Стратификационный подход в изучении речи горожан // Перспективы науки. 2018. № 9(108). С. 283-286.

Зайковская Т. В. Пути пополнения лексического состава современного молодежного жаргона: Автореф. дис. ... канд. филол. наук. M., 1993. 20 c.

Земская Е. А., Китайгородская М. В., Ширяев Е. Н. Русская разговорная речь: Общие вопросы. Словообразование. Синтаксис. М.: Наука, 1981. 276 с. 
Земская Е. А. Русская разговорная речь: Лингвистический анализ и проблемы обучения. М.: Русский язык, 1979. 240 с.

Ковалева Л. С., Кабулова Л. Т. Экспрессивный потенциал грамматической категории рода в сниженных стилях // Язык и эмоции. Волгоград, 1995. С. 115-124.

Лексикографическое описание народноразговорной речи современного города: теор. аспекты. ОмГУ / Осипов Б. И., Боброва Г. А., Имедадзе Н. А.и др. Омск: Омский гос. ун-т, б.и., 1994. 144 с.

Малинина Н. В. Устная речь в структуре художественного текста (разговорная речь и жаргон) // Русский язык и литература в пространстве мировой культуры. Материалы XIII Конгресса МАПРЯЛ. В 15 томах. 2015. C. 397-400.

Малькова Г. А. Разновидности национального языка: жаргон, сленг, арго // Актуальные проблемы теории языка, перевода, межкультурной коммуникации и методики преподавания. Сборник статей. Отв. ред. Н.В. Бутылов. Вып. 1. Саранск: ИП Афанасьев B.C, 2018. C. 44-47.

Потебня А. А. Из записок по русской грамматике. М.: Просвещение, 1968. Т.3. 551 с.

Скворцов Л. И. Теоретические основы культуры речи. М.: Наука, 1980. 352 с.

Тимофеев В. П. Социолингвистические факторы в развитии современного русского языка // Очерки по социолингвистике. Шадринск: ШГПИ, 1971. С. 9-28.

Федяев С. М. Уголовное арго ХХ в. как объект лингвистического исследования // Природа. Общество. Человек. Краснодар, (5-6) 1996. № 2-3.

Хан-Пира Э. Зек (зэк) // Русская речь. № 3. 1994. C. 44-46.

Calvet L.-J. L'Argot en 20 leçons. Paris: Editions Payot \& Rivages, 1993. 215 p.

Calvet L.-J. Les voix de la ville: Introduction à la sociolinguistique urbaine. P.: Payot, 1994. 309 p.

François D. Les argots // Le langage: Encyclopédie de la Pléiade. P.: Gallimard, 1973. P. 620-625 .

François-Geiger D. Introduction à la première édition // Colin J.-P., Mével J.-P., Leclère C. Dictionnaire de l'argot français et de ses origines. Larousse, 2002.

Fried M., Östman J.-O., Verschueren J. Variation and Change: Pragmatic Perspectives.
Amsterdam, Philadelphia: John Benjamin Publishing Company, 2010. 277 p.

Les Argots de Métiers Franco-Provençaux (Classic Reprint). Fb\&c Limited, 2018. 288 p.

Verdelhan-Bourgade M. Procédés sémantiques et lexicaux en français branché // $\mathrm{La}$ langue française. 1991. № 90. Р. 65-79.

Список словарей

Быков В. Русская феня. Словарь современного интержаргона асоциальных элементов. Смоленск, 1993.

Елистратов В. С. Словарь московского арго: Материалы 1980-1994 гг. М., 1994.

Ожегов С. И. Словарь русского языка. М., 1953, 1972, 1984, 1989.

Ожегов С. И. и Шведова Н. Ю. Толковый словарь русского языка. М., 1995.

Словарь молодежного жаргона / Под ред.

И. А. Стернина. Воронеж, 1992.

Словарь русского языка: в 4-х томах /

АН СССР Ин-т рус. яз. Под ред А. П. Евгеньевой. М., 1985-1988.

Словарь тюремно-лагерно-блатного жаргона: Речевой и графический портрет советской тюрьмы. М., 1992.

Colin J.-P., Mével J.-P., Leclère C. Dictionnaire d'argot. Larousse, 1991.

Dictionnaire de la langue française. Lexis. Larousse, 1992.

\section{References}

Barnet, V. (1988). Differentiation of the national language and social communication, New in foreign linguistics: The theory of literary language in the works of scientists of Czechoslovakia, XX,188-198. (in Russian).

Beregovskaya, E. M. (1975). Sotsial'nye dialekty $i$ yazyk sovremennoi frantsuzskoi prozy [Social dialects and the language of modern French prose]. Smolensk, Russia: Smolenskii pedagogicheskii institut. (in Russian).

Bykov, V. (1993). Russkaya fenya. Slovar' sovremennogo interzhargona asotsial'nyh elementov [Russian fenya. Dictionary of modern interjargon of antisocial elements], Smolensk, Russia (in Russian).

Vandries, ZH. (1937). YAzyk: Lingvisticheskoe vvedenie $v$ istoriyu. [Language: Linguistic Introduction to History] Moscow, Russia: Gosudarstvennoe sotsial'no-ekonomicheskoe izdatel'stvo (in Russian).

Vinogradova, V. N. (1984). Stilisticheskii aspekt russkogo slovoobrazovaniya [The stylistic 
aspect of Russian word formation], Moscow, Russia: Nauka. (in Russian).

Vinokur, T. G. (1968). Stilisticheskoe razvitie sovremennoi russkoi razgovornoi rechi [Stylistic development of modern Russian colloquial speech], ed. By D.N. Shmelev Development of functional styles of the modern Russian language. Moscow, Russia: Nauka. (in Russian).

Gak, V. G. (1966). Besedy o frantsuzskom slove (Iz sravnitel'noi leksikologii russkogo $i$ frantsuzskogo yazykov) [Conversations about the French word (From the comparative lexicology of the Russian and French languages)]. Moscow, Russia.: Mezhdunarodnye otnosheniya. (in Russian).

Gerd, A. S. (2016). Jargon and social group, Questions of psycholinguistics, № 28, 106-111.

Grachev, M. A. (1995). The origin and functioning of Russian argo. Abstract of Ph.D thesis, Sankt-Peterburg, Russia. (in Russian).

Dictionary of youth jargon. (1992). Voronezh, Russia (in Russian).

Dictionary of the Russian language: in 4 volumes, Moscow, Russia: AN SSSR In-t rus. yaz.

Dictionary of the French language. Dictionnaire de la langue française. Lexis. (1992). Larousse, France.

Slovar' tyuremno-lagerno-blatnogo zhargona: Rechevoi i graficheskii portret sovetskoi tyur'my [Dictionary of prison camp slang: Speech and graphic portrait of a Soviet prison]. (1992). Moscow, Russia. (in Russian).

Dobrieva, Z. I., Izmailova, M. M. (2017). Jargon in the speech of modern youth, Linguauniversum, № 4, 33-35. (in Russian).

Elistratov, V. S. (1995). Argo i kul'tura, [Argot and culture]. Moscow, Russia: Moscow State University. (in Russian).

Elistratov, V. S. (1980-1994). Slovar' moskovskogo argo: Materialy 1980-1994 gg. [Dictionary of Moscow Argo: Materials 1980-1994]. Moscow, Russia 1994. (in Russian).

Erofeeva, T. I. (1991). Opyt issledovaniya rechi gorozhan. [Experience in the study of the speech of citizens], Sverdlovsk, Russia: Ural'skii universitet. (in Russian).

Erofeeva, T. I. (2018). A stratification approach in the study of the speech of citizens, Perspektivy nauki, № 9 (108), 283-286. (in Russian).

Zaikovskaya, T. V. (1993). Ways to replenish the lexical composition of modern youth jargon, abstract of Ph.D Moscow, Russia. (in Russian).
Zemskaya, E. A., Kitaigorodskaya, M. V., Shiryaev, E. N. (1981). Russkaya razgovornaya rech': Obshchie voprosy. Slovoobrazovanie. Sintaksis, [Russian Conversation: General Issues. Word formation]. Moscow, Russia: Nauka. (in Russian).

Zemskaya, E. A. (1979). Russkaya razgovornaya rech': Lingvisticheskii analiz i problemy obucheniya, [Russian spoken language: Linguistic analysis and problems of learning], Moscow, Russia: Russkij yazyk. (in Russian)

Kovaleva, L. S., Kabulova, L. T. (1995). The expressive potential of the grammatical category of the genus in reduced styles, YAzyk $i$ emotsii, 115-124.

Osipov B.I., Bobrova G.A. and Imedadze N.A. (1994). Leksikograficheskoe opisanie narodno-razgovornoi rechi sovremennogo goroda: teoreticheskie. aspekty [Lexicographic description of the colloquial speech of a modern city: theoretical aspects], Omsk, Russia: Omskii gos. Un-t. (in Russian).

Malinina, N. V. (2015). Oral speech in the structure of a literary text (colloquial speech and jargon), Russkij yazyk i literatura $v$ prostranstve mirovoj kul'tury. XIII Kongress MAPRYAL, 97-400.

Mal'kova, G. A. (2018). Varieties of the national language: jargon, slang, argo, Aktual'nye problemy teorii yazyka, perevoda, mezhkul'turnoi kommunikatsii i metodiki prepodavaniya, 44-47.

Ozhegov, S. I. (1953, 1972, 1984, 1989).

Slovar' russkogo yazyka. [Dictionary of the Russian language]. M., Russia. (in Russian).

Ozhegov, S. I. and Shvedova, N. YU. (1995). Tolkovy slovar' russkogo yazyka. [Explanatory dictionary of the Russian language]. Moscow, Russia. (in Russian)

Potebnya, A. A. (1968). Iz zapisok po russkoi grammatike, [From the notes on Russian grammar], Moscow, Russia: Prosveshchenie.

Skvortsov, L. I. (1980). Teoreticheskie osnovy kul'tury rechi, [Theoretical foundations of speech culture]. Moscow, Russia.: Nauka.

Timofeev, V. P. (1971). Sociolinguistic factors in the development of the modern Russian language, Ocherki po sociolingvistike,9-28. (in Russian).

Fedyaev, S. M. (1996). Criminal argot of the twentieth century as an object of linguistic research, Priroda. Obshchestvo. Chelovek. Krasnodar, (5-6), № 2-3, 43-45. (in Russian). 
Han-Pira, E. (1994). Z'ek (zek), Russkaya rech'. №3, 44-46. (in Russian).

Calvet L.-J. (1993). The Slang in 20 lessons. L'Argot en 20 leçons. Paris, France: Editions Payot \& Rivages.

Calvet, L.-J. (1994). The voices of the city: Introduction to urban sociolinguistics. Les voix de la ville: Introduction à la sociolinguistique urbaine. R.: Payot.

Colin, J.-P., Mével, J.-P., Leclère C. (1991). Dictionnaire d'argot. Larousse, 1991.

Franois, D. (1973). Slangs Language: Encyclopedia of the Pleiades. Les argots, R.: Gallimard.

Franois-Geiger, D. (2002). Introduction to the first edition [Introduction à la première édition], Larousse.

Östman, J.-O., Verschueren J. (2010). Variation and Change: Pragmatic Perspectives. Amsterdam, Philadelphia: John Benjamin Publishing Company.

The Franco-Provençal Trade Argots (Classic Reprint). Les Argots de Métiers FrancoProvençaux (Classic Reprint). (2018). Fb\&c Limited.

Verdelhan-Bourgade, M. (1991). The French language. Procédés sémantiques et lexicaux en franais branché, La langue franaise.,№ 90, 65-79.
Конфликты интересов: у авторов нет конфликта интересов для декларации.

Conflicts of Interest: the authors have no conflict of interest to declare.

Хорошева Наталья Владимировна, кандидат филологических наук, доцент кафедры лингвистики и перевода Пермского государственного национального исследовательского университета.

Шустова Светлана Викторовна, доктор филологических наук, доцент, профессор кафедры лингвистики и перевода Пермского государственного национального исследовательского университета.

Natalya V. Khorosheva, $\mathrm{PhD}$ in Philology, Associate Professor, Department of Linguistics and Translation, Perm State National Research University, 15 Bukirev St., Perm, 614990, Perm Kr., Russia

Svetlana V. Shustova, Grand PhD of Philology, Associate Professor, Professor, Department of Linguistics and Translation, Perm State National Research University. 